\title{
Suicidal Thought in the Adolescent: Exploring the Relationship Between Known Risk Factors and the Presence of Suicidal Thought
}

\author{
Cana M. Shimshock, MSN, RN, Reg Arthur Williams, PhD, RN, BC, FAAN, and \\ Barbara-Jean B. Sullivan, PhD, PMHCNS-BC, NP
}

Cana M. Shimshock, MSN, RN, is a Doctoral Student, School of Nursing; Reg Arthur Williams, PhD, RN, BC, FAAN, is Professor, School of Nursing and Psychiatry, Medical School; Barbara-Jean B. Sullivan, PhD, PMHCNS-BC, NP, is Assistant Clinical Professor, School of Nursing, University of Michigan, Ann Arbor, MI, USA.

\section{Search terms:}

Adolescent, Navy recruit, risk factor, sense of belonging, suicidal thought

\section{Author contact:}

cmshims@umich.edu, with a copy to the

Editor: poster@uta.edu

doi: 10.1111/j.1744-6171.2011.00310.x
PROBLEM: The purpose of this retrospective study was to explore the relationship between recognized risk factors for suicidal thought and the presence or absence of self-reported suicidal thought.

METHODS: This study was conducted through the secondary analysis of data obtained from a larger, prospective, cluster-randomized intervention study. A subset of 817 recruits between the ages of 17 and 19 was included in this study.

FINDINGS: A personal history of mental health/emotional problems and a decreased sense of belonging made unique contributions to predicting the presence of suicidal thought.

CONCLUSIONS: The development of interventions to increase sense of belonging may be a key to reducing suicidal thought during stressful events.
Following unintentional injuries and homicide, suicide is the third leading cause of death among adolescents in the United States, ages 15-24 (National Center for Health Statistics, 2010). For 1 year alone, the total cost for medical care and lost productivity related to suicide in this age group was estimated to be $\$ 7.1$ billion dollars (Corso, Mercy, Simon, Finkelstein, \& Miller, 2007). In an attempt to address this problem, Healthy People 2010 listed as one of its national objectives the reduction of adolescent suicide attempts from a 1999 12-month average of $2.6 \%$ in grades 9 through 12 to a 12 -month average of $1 \%$ by 2010 (U.S. Department of Health and Human Services, 2000). The national objectives for Healthy People 2020 broaden the scope of the 2010 goal to encompass a reduction in suicide among all adolescent groups, as well as the provision of school-based prevention information (U.S. Department of Health and Human Services, 2011). Before effective interventions can be developed, however, it is imperative that at-risk adolescents are identified with greater accuracy, using risk factors of greater specificity to the phenomenon (Bursztein \& Apter, 2009). A step toward the accomplishment of this goal is an exploration of risk factors that are recognized as being linked to the development of suicidal thought, and determining their actual impact on the development of suicidal thought in the adolescent.

\section{Purpose}

The purpose of this retrospective study was to explore the relationship between recognized risk factors for suicidal thought (i.e., family history of mental illness; use or abuse of drugs and/or alcohol; loss of a parent; personal history of physical, sexual, emotional, and/or verbal abuse; decreased sense of belonging) and the presence or absence of self-reported suicidal thought.

\section{Background}

In a Navy recruit study, researchers evaluated the effect of a cognitive/behavioral intervention on divisions of Navy recruits (Williams et al., 2007). Almost 75\% of participants were in late adolescence (ages 17-19), with the following data being collected via self-report instruments: psychiatric disorders, alcohol and drug abuse in their family, loss of a parent, childhood maltreatment, suicidal thought, and sense of belonging (Williams et al., 2007). Therefore, this study is a retrospective secondary analysis of the larger study, with a specific focus on the risk factors believed to impact suicidal thought.

Suicide research has identified several risk factors that may increase an individual's potential for suicide. One such risk 
factor, childhood maltreatment, has been linked to both attempted and completed suicide (Borowsky, Ireland, \& Resnick, 2001; Brent, Baugher, Bridge, Chen, \& Chiappetta, 1999). In children where the abuse was sexual in nature, the rate of attempted suicide was two to four times greater, with the abuse survivor being considered at high-risk for future suicidal behavior (Molnar, Berkman, \& Buka, 2001).

Another risk factor, parental loss, encompasses the loss of a parent through death, divorce, or separation, and has been linked to death by suicide (Agerbo, Nordentoft, \& Mortensen, 2002; Grøholt, Ekeberg, Wichstrøm, \& Haldorsen, 2000). In addition, the death of a parent prior to the child's 12th birthday has shown an increase in the number of repeat suicide attempts within the affected children in that group (Lewinsohn, Rohde, \& Seeley, 1996).

A strong link has been shown between the presence of psychiatric disorders and both suicidal ideation and attempt (Gould et al., 1998; Pfeffer, 2001; Shafii, Steltz-Lenarsky, Derrick, Beckner, \& Whittinghill, 1988). Almost 90\% of adolescent suicide victims have some type of psychiatric disorder, a finding that translates into a greater risk for suicide attempt among adolescents currently living with such disorders (Shaffer, Gould, Fisher, \& Trautman, 1996). In addition to the adolescent's personal history, a parental history of psychiatric disorders, such as affective, disruptive, psychotic, and/or personality disorders, has also been proven to increase the adolescent's risk of suicide attempt (Brent, 1995; Shaffer et al., 1996). In those who die by suicide, researchers have often found a family history of mental illness or suicidal behavior (Agerbo et al., 2002; Borowsky et al., 2001; Brent \& Mann, 2005; Gould et al., 1998).

Substance use in the form of alcohol or drug use or abuse is also an established risk factor for suicide when it occurs in the presence of either a disruptive or mood disorder (Borowsky et al., 2001; Shaffer et al., 1996). When considered independently from disruptive or mood disorders, substance use itself has been found to be more prevalent in adolescent suicide attempters than in adolescents with suicidal ideation, indicating that substance abuse may contribute to the escalation of suicidal ideation to suicide attempt (Gould et al., 1998).

Research indicates a relationship between the psychological experience of sense of belonging and psychological and personal well-being (Hagerty, Williams, Coyne, \& Early, 1996). When considering suicidal thought in particular, the psychological experience of sense of belonging has been shown to have an inverse relationship with suicidal thought, ideation, and attempt (Hagerty et al., 1996; Hill, 2009).

\section{Methods}

This study was conducted through the secondary analysis of data obtained from a larger, prospective, cluster-randomized intervention study whose purpose was to examine the effect of a cognitive/behavioral intervention on depression (Williams et al., 2007). Data were extracted and analyzed based on their relationship to the following: recognized risk factors for suicidal thought, the presence of suicidal thought itself, and the level of individual sense of belonging.

\section{Sample}

There were 1,199 Navy recruits in basic training at the Great Lakes Naval Recruit Training Command who participated in the larger study (Williams et al., 2007). For the present study, a subset of 17-, 18-, and 19-year-old recruits was drawn from the larger study. Of the 817 subjects in this study sample, the proportion of males $(75.6 \%)$ versus females $(24.4 \%)$ remained largely the same in each age group, with 18 -year-old subjects comprising the majority of the sample (57.3\%). Most participants reported never having been married and lived with their parents at the time of their joining the Navy. The ethnicity of the majority of the sample was Caucasian followed by African American and Hispanic. See Table 1 for a complete breakdown of demographic characteristics.

\section{Measures}

\section{Background Information}

The participants provided both personal and family demographic information, including age, gender, marital status, ethnicity, and education, as well as a history of various types of abuse. For this retrospective study, data in the following areas were evaluated: family history of mental illness or emotional problems; family history of heavy alcohol use or abuse; family history of drug use or abuse; personal history of physical abuse; personal history of sexual abuse; and personal history of emotional/verbal abuse. Responses to the questions were indicated as yes or no (Sargent, Williams, Hagerty, Lynch-Sauer, \& Hoyle, 2002).

\section{Beck Depression Inventory-Second Edition}

The 21-item Beck Depression Inventory-Second Edition (BDI-II) uses self-report to evaluate the motivational, cognitive, affective, psychomotor, and vegetative features of depression in both adults and adolescents (Beck, Steer, \& Brown, 1996). Both internal consistency and test-retest correlation have been measured between .92 and .93 , with strong concurrent validity being noted when the instrument is compared with other depression measures and clinicians' depression ratings (Beck et al., 1996). Discriminant validity has been shown with other disorders (Beck et al., 1996). The adjusted Cronbach's $\alpha$ reliability coefficient for the Strategies to Assist Navy Recruits' Success (STARS) study was .87 at the first week of training and .86 at week 9 of completion of training 
Table 1. Individual Characteristics as a Percentage of the Sample $(n=817)$

\begin{tabular}{|c|c|c|}
\hline Characteristic & Percentage & $n$ \\
\hline \multicolumn{3}{|l|}{ Age } \\
\hline 17 & 7.1 & 58 \\
\hline 18 & 57.2 & 467 \\
\hline 19 & 35.7 & 292 \\
\hline \multicolumn{3}{|l|}{ Gender } \\
\hline Male & 75.4 & 616 \\
\hline Female & 24.6 & 201 \\
\hline \multicolumn{3}{|l|}{ Ethnicity } \\
\hline African American & 17.3 & 139 \\
\hline Asian American & 2.5 & 20 \\
\hline Caucasian & 61.1 & 492 \\
\hline Hispanic & 13.9 & 112 \\
\hline Native American & 1.9 & 15 \\
\hline Other & 3.4 & 27 \\
\hline \multicolumn{3}{|l|}{ Marital status } \\
\hline Never married & 87.1 & 700 \\
\hline Engaged or living with significant other & 10.0 & 80 \\
\hline Married & 2.7 & 22 \\
\hline Separated & 0.2 & 2 \\
\hline \multicolumn{3}{|l|}{ Education } \\
\hline Less than high school or equivalent & 1.9 & 15 \\
\hline Graduated high school & 83.0 & 668 \\
\hline Completed GED & 3.4 & 27 \\
\hline Some college or trade school & 11.8 & 95 \\
\hline \multicolumn{3}{|l|}{ Living arrangements prior to enlistment } \\
\hline Lived alone & 1.5 & 12 \\
\hline Lived with parents & 75.0 & 604 \\
\hline Lived with other relatives & 6.6 & 53 \\
\hline Lived with roommate(s) & 4.0 & 32 \\
\hline Lived with girlfriend/boyfriend & 5.3 & 43 \\
\hline Lived with spouse & 2.0 & 16 \\
\hline Other & 5.6 & 45 \\
\hline \multicolumn{3}{|l|}{ Employment status prior to enlistment } \\
\hline Not employed & 28.8 & 232 \\
\hline Employed part-time & 41.0 & 330 \\
\hline Employed full-time & 30.2 & 243 \\
\hline
\end{tabular}

Note: GED = general equivalency degree.

(Williams et al., 2007). Because of its specificity to the presence or absence of suicidal thought, only BDI-II item number 9 was used for this retrospective study.

\section{Childhood Adversity and Adolescence Deviance Instrument}

The Childhood Adversity and Adolescence Deviance Instrument (CAAD) was first developed by Kupfer, Detre, and Koral (1974), with modifications made by Cohen, Coyne, and Duvall (1996). The current instrument measures the presence or absence of 16 adversities that may have occurred during childhood, as well as 12 adversities that may have arisen in high school (Hagerty, Williams, \& Oe, 2002). Each question in the CAAD was answered by yes or no. For this retrospective study, CAAD items pertaining to the risk factors for suicide were used, specifically: personal history of parental separa- tion or divorce, personal history of parental death, personal history of heavy alcohol abuse, personal history of mental health/emotional problems, personal history of incest, and personal history of violence or abuse toward children (Cohen, Coyne, \& Duvall, 1996).

\section{Sense of Belonging Instrument-Psychological}

The Sense of Belonging Instrument-Psychological (SOBI-P) is an 18-item instrument measuring an individual's psychological experience of sense of belonging (Williams et al., 2004). As reported by Hagerty and Patusky (1995), the SOBI-P has demonstrated content and construct validity, as well as reliability as evidenced by a Cronbach's $\alpha$ coefficient of .93. In the current study, the Cronbach's $\alpha$ coefficient was .91.

\section{Procedures}

Data were collected in a division of recruits in the first week of their 9-week training schedule. The data collection period for all of the divisions was over 18 months.

\section{Analysis}

Statistical analysis for this study was conducted using PASW Statistics 18.0 for Windows (SPSS Inc., Chicago, IL, USA). Descriptive statistics were used to determine the frequency of demographic characteristics, risk factors for suicide, and the presence of suicidal thought. Chi-square analysis was performed to determine the relationship between suicidal thought and each of the recognized risk factors, followed by logistic regression to determine the strength of these relationships.

\section{Results}

On a scale of 0 (no depressive symptoms) to 63 (severe depressive symptoms) for the BDI-II, the severity of depressive symptoms in the sample was mild $(M=15.54, S D=9.62$, $n=817$ ). An evaluation of the frequency of suicidal thought and its recognized risk factors revealed that $13 \%$ of the sample reported suicidal thought, with the risk factors related to childhood maltreatment and the loss of a parent occurring with the greatest frequency (Table 2).

A $\chi^{2}$ test for independence (with Yates' continuity correction) indicated a higher rate of suicidal thought among those who reported having one or more recognized risk factors. However, a significant association was found between suicidal thought and only half of the risk factors being evaluated (Table 3).

Logistic regression was performed to assess the impact of risk factors for suicidal thought on the likelihood that respondents who reported a history of the risk factors for sui- 
cidal thought would, in fact, report having suicidal thought. Two models were tested, the first containing the six independent variables found in the $\chi^{2}$ analysis to have a statistically significant relationship to suicidal thought (i.e., family

Table 2. Frequency of Suicidal Thought and Risk Factors for Suicide as a Percentage of the Sample $(n=817)$

\begin{tabular}{lll}
\hline Risk factor & Percentage & $\boldsymbol{n}$ \\
\hline Presence of suicidal thought & 13 & 106 \\
Personal history & & \\
Parental separation or divorce & 48.7 & 387 \\
Emotional/verbal abuse & 20.9 & 168 \\
Heavy alcohol use & 13 & 103 \\
Mental/emotional problems & 12.1 & 96 \\
Physical abuse & 9.7 & 78 \\
Child abuse/violence & 9.1 & 72 \\
Parental death & 7.3 & 58 \\
Sexual abuse & 4.1 & 33 \\
Incest & 0.5 & \\
Family history & & 277 \\
Heavy alcohol use or abuse & 33.9 & 183 \\
Drug use/abuse & 22.4 & 156 \\
Mental/emotional problems & 19.1 & \\
\hline
\end{tabular}

history of mental/emotional problems, family history of drug use/abuse, personal history of sexual abuse, personal history of emotional/verbal abuse, personal history of mental health/ emotional problems, and personal history of violence/abuse toward children). The second model included the same six variables, with the addition of the SOBI-P.

The first model containing only the six independent predictors was statistically significant, $\chi^{2}(6, n=817)=33.57$, $p<.001$, indicating that the model was able to distinguish between respondents who reported and did not report suicidal thought. The model as a whole explained between $4.2 \%$ (Cox and Snell $R^{2}$ ) and 8\% (Nagelkerke $R^{2}$ ) of the variance in suicidal thought, and correctly classified $87.4 \%$ of cases. As shown in Table 4, only a personal history of mental health/ emotional problems made a unique, statistically significant contribution to the model, with an odds ratio of 2.87 $(p<.001)$ (Table 4$)$.

The second model containing the six independent predictors, in addition to the SOBI-P, was statistically significant, $\chi^{2}$ $(7, n=817)=37.40, p<.001$, indicating that this model was also able to distinguish between respondents who reported and did not report suicidal thought. As a whole, this model explained between $8.7 \%$ (Cox and Snell $R^{2}$ ) and 16.5\%

Table 3. Suicidal Thought and the Presence or Absence of Specific Risk Factors

\begin{tabular}{|c|c|c|c|c|c|}
\hline Risk factor & $\begin{array}{l}\text { Percentage with } \\
\text { Suicidal Thought }\end{array}$ & $\begin{array}{l}\text { Percentage Without } \\
\text { Suicidal Thought }\end{array}$ & $\chi^{2}$ & $d f$ & $p$ \\
\hline \multicolumn{6}{|l|}{ Personal history } \\
\hline Parental separation or divorce & 13.7 & 11.3 & 1.04 & 1 & .308 \\
\hline Emotional/verbal abuse & 23.2 & 9.9 & 21.33 & 1 & $<.001 *$ \\
\hline Heavy alcohol use & 17.5 & 11.7 & 2.72 & 1 & .099 \\
\hline Mental/emotional problems & 29.2 & 10.2 & 27.90 & 1 & $<.001 *$ \\
\hline Physical abuse & 17.9 & 12.1 & 2.17 & 1 & .140 \\
\hline Child abuse/violence & 20.8 & 11.6 & 5.08 & 1 & $.024^{*}$ \\
\hline Parental death & 12.1 & 12.5 & 0.01 & 1 & .924 \\
\hline Sexual abuse & 33.3 & 11.8 & 13.28 & 1 & $.001 *$ \\
\hline Incest & 25.0 & 12.4 & 0.58 & 1 & .414 \\
\hline \multicolumn{6}{|l|}{ Family history } \\
\hline Heavy alcohol use or abuse & 14.4 & 11.7 & 1.20 & 1 & .274 \\
\hline Drug use/abuse & 18.0 & 11.1 & 6.15 & 1 & $.013^{*}$ \\
\hline Mental/emotional problems & 20.5 & 10.8 & 10.75 & 1 & $.001 *$ \\
\hline
\end{tabular}

* $p<.05$

\begin{tabular}{lrlccc}
\hline Risk factor & Wald & $\boldsymbol{d f}$ & $\boldsymbol{p}$ & OR & $\mathbf{9 5 \%} \mathbf{~ C I}$ \\
\hline Personal history & & & & & \\
$\quad$ Emotional/verbal abuse & 3.48 & 1 & .06 & 1.73 & {$[0.97,3.08]$} \\
$\quad$ Mental/emotional problems & 13.42 & 1 & $<.001^{*}$ & 2.86 & {$[1.63,5.03]$} \\
$\quad$ Child abuse/violence & 0.41 & 1 & .52 & 0.78 & {$[0.37,1.67]$} \\
$\quad$ Sexual abuse & 2.88 & 1 & .09 & 2.16 & {$[0.89,5.24]$} \\
Family history & & & & & \\
$\quad$ Drug use/abuse & 0.02 & 1 & .89 & 1.04 & {$[0.60,1.79]$} \\
$\quad$ Mental/emotional problems & 0.63 & 1 & .43 & 1.25 & {$[0.72,2.18]$} \\
\hline
\end{tabular}

Table 4. Logistic Regression Predicting Likelihood of Reporting Suicidal Thought When Having a Risk Factor

$\mathrm{Cl}$, confidence interval; OR, odds ratio.

$* p<.05$ 
Table 5. Logistic Regression Predicting Likelihood of Reporting Suicidal Thought When Having a Risk Factor

\begin{tabular}{lccccc}
\hline Risk factor & Wald & $\boldsymbol{d} \boldsymbol{f}$ & $\boldsymbol{p}$ & $\mathbf{O R}$ & $\mathbf{9 5 \%} \mathbf{C I}$ \\
\hline Personal history & & & & & \\
$\quad$ Emotional/verbal abuse & 0.86 & 1 & .35 & 1.33 & {$[0.73,2.41]$} \\
$\quad$ Mental/emotional problems & 5.95 & 1 & $.01^{*}$ & 2.08 & {$[1.15,3.75]$} \\
$\quad$ Child abuse/violence & 0.63 & 1 & .43 & 0.73 & {$[0.33,1.59]$} \\
$\quad$ Sexual abuse & 1.68 & 1 & .19 & 1.87 & {$[0.72,4.83]$} \\
Family history & & & & & \\
$\quad$ Drug use/abuse & 0.15 & 1 & .69 & 0.89 & {$[0.51,1.57]$} \\
$\quad$ Mental/emotional problems & 0.05 & 1 & .83 & 1.07 & {$[0.60,1.89]$} \\
$\quad$ SOBI-P & 35.31 & 1 & $<.001^{*}$ & 0.94 & {$[0.92,0.96]$} \\
\hline
\end{tabular}

$\mathrm{Cl}$, confidence interval; OR, odds ratio; SOBI-P, Sense of Belonging Instrument-Psychological. $* p<.05$
(Nagelkerke $R^{2}$ ) of the variance in suicidal thought, as well as correctly classifying $87.6 \%$ of cases. Similar to the first model, personal history of mental health /emotional problems made a unique, statistically significant contribution to the model, with an odds ratio of $2.08(p<.015)$ (Table 5$)$.

\section{Discussion}

The aim of this retrospective study was to explore the relationship between recognized risk factors for suicide and the presence or absence of self-reported suicidal thought. The sample used for this analysis reported a rate of suicidal thought equaling $13 \%$, which is comparable to the $13.1-14.6 \%$ of adolescents nationwide who report considering suicide (Centers for Disease Control and Prevention, 2010).

In this sample, one-half of the risk factors for suicide were found to have a statistically significant association to suicidal thought: family history of mental illness/emotional problems and drug use/abuse, and personal history of sexual abuse, emotional/verbal abuse, mental health/emotional problems, and violence/abuse toward children. These results confirm the findings of other researchers and provide further support for the continued investigation of their role in the development of suicidal thought in the adolescent (Agerbo et al., 2002; Brent, 1995; Gould et al., 1998; Molnar et al., 2001). The remaining six risk factors, however, did not reflect statistically significant relationships with suicidal thought, and plausible explanations for these results are offered.

The absence of a significant relationship between suicidal thought and a personal history of physical abuse or incest, as well as a family history of heavy alcohol use or abuse, was significantly different from the findings of other researchers (Borowsky et al., 2001; Brent et al., 1999; Gould et al., 1998; Lawson, 2009; Molnar et al., 2001; Shaffer et al., 1996). This may be due to differences in the type, severity, and length of risk factor exposure among participants (Dube et al., 2001). In addition, the cumulative effects of each risk factor, as well as the relationship between the risk factors themselves, may result in the development of suicidal thought later in the life span (Dube et al., 2001). Another factor affecting these results may be differences among subjects in their interpretation of the inclusion criteria for specific risk factors. Because the definitions of abuse and maltreatment can vary across cultures, the quantification of risk factor criteria may provide further insight into the relationship between variables (May-Chahal \& Cawson, 2005).

When considering parental death, the absence of a significant relationship to suicidal thought may be related to the cause of the parental death experienced by the child. Research comparing the depressive symptoms of children who suffered parental loss through a long-term disease, such as cancer, versus a sudden event, such as suicide, revealed a higher level of depressive symptoms and interpersonal problems among the second group (Pfeffer, Karus, Siegel, \& Jiang, 2000). It is possible that the participants who reported the death of a parent may have suffered the loss through a long-term illness, which may lessen the incidence of suicidal thought.

In regard to parental divorce, the results of this analysis did not support earlier findings indicating a relationship between divorce and suicide (Agerbo et al., 2002; Grøholt et al., 2000). It did, however, support emerging data that reflects the decreasing role of the divorce on the development of suicidal thought (Afifi, Boman, Fleisher, \& Sareen, 2009; Goldstein et al., 2009; Hardt et al., 2008). One study has suggested that divorce, when treated as a static event, does not play a role in suicidality so much as the way in which family members function and interact with one another before, during, and after the event (Goldstein et al., 2009). Thus, the absence of a statistically significant relationship between parental divorce and suicidal thought lends credence to the concept of divorce being a multifaceted process instead of a static event. In addition, the increased incidence of divorce has resulted in many adolescents finding themselves in the majority of their peers instead of a unique and separate minority. As a result of this change in societal dynamics, it is possible that today's adolescents no longer suffer from the stigma previously associated with parental divorce and this, in turn, has lessened the 
impact of divorce on the development of suicidal thought. Logistic regression was performed using two scenarios, the first of which contained the six risk factors found to be noteworthy in the $\chi^{2}$ analysis. This model was statistically significant, indicating that it was able to distinguish between respondents who confirmed or denied having suicidal thought (Table 4). Only a personal history of mental health/ emotional problems made a unique statistically significant contribution to the model, thus indicating that such respondents were almost three times as likely to report suicidal thought as those who did not have a personal history of mental health/emotional problems. Logistic regression was performed a second time using the same six risk factors, with the addition of the SOBI-P. This model was also able to distinguish between respondents who confirmed or denied suicidal thought, and, similar to the first model, a personal history of mental health/emotional problems made a unique statistically significant contribution to the model, as did the SOBI-P (Table 5).

In both logistic regression models, respondents who had a personal history of mental health/emotional problems were over twice as likely to report suicidal thought as those who did not have a personal history of such problems. While these results confirm earlier research connecting mental illness and suicidal thought (Agerbo et al., 2002; Brent, 1995; Gould et al., 1998), the lack of a statistically significant relationship between suicidal thought and the five remaining risk factors did not support the association reported by other researchers (Agerbo et al., 2002; Brent, 1995; Molnar et al., 2001). The inclusion of the SOBI-P in the second model resulted in a larger proportion of explained variance and reinforced earlier research showing an inverse relationship between the SOBI-P and suicidal thought (Hagerty et al., 1996; Hill, 2009). The relative small amount of explained variance may be attributed to the young age and reasonably good health of the study population. Moreover, the complexity of the predictors of suicidal thought adds to a larger proportion that is explained by other variables not included in this study. A sense of belonging provides an important addition to better understanding this complexity and opens a new direction to better examine the risk factors that increase suicidal thought.

The high rate of suicide among returning U.S. Army veterans has not decreased despite the implementation of tailored interventions to improve the identification and treatment of those determined to be at risk (McKinley, 2010). In light of this continuing problem, the role played by sense of belonging in this study may have important implications to potentially impact depression and, by extension, suicidal thought (Goldney, Wilson, Dal Grande, Fisher, \& McFarlane, 2000; McLaren \& Challis, 2009). The ameliorating effect of sense of belonging on the development of depressive symptoms has been documented in Navy recruits, with the effect being more profound among those with a family history of alcohol abuse
(Sargent et al., 2002). In a qualitative study of returning combat veterans, sense of belonging appeared to be inversely related to the ease with which subjects raised the topic of suicide during their interviews (Brenner et al., 2008). These results hold promise as evidence that sense of belonging may be used as a point of intervention in the path to suicidal thought and provide evidence to the theory proposed by Van Orden and colleagues (Van Orden et al., 2010).

\section{Study Limitations}

A limitation of the study was the absence of specific information regarding the risk factors. This limited the analysis of their impact on suicidal thought. Causes of parental death, general descriptions of the abuse being reported, and the ages at which adverse events occurred would have allowed a greater understanding of the roles played by these risk factors and the points at which their effect could be minimized.

\section{Implications for Nursing Practice and Research}

In this sample, personal history of mental/emotional problems was found to have a statistically significant relationship to suicidal thought. Unlike previous research, this study did not find significant relationships between the remaining risk factors and suicidal thought. The contribution of sense of belonging to understanding suicidal thought is an important finding. The development of interventions to increase sense of belonging may be a key to reducing suicidal thought during stressful events. Furthermore, a greater understanding of the role played by sense of belonging at this transitional stage of adolescent development could better our understanding of this very important, yet vulnerable time.

\section{Acknowledgments}

This research was sponsored in part by the TriService Nursing Research Program (TSNRP \#98-054, MDA \#905-98-0026), Uniformed Services University of the Health Sciences; however, the information or content and conclusions do not necessarily represent the official position or policy of, nor should any official endorsement be inferred by, the TriService Nursing Research Program, Uniformed Services University of the Health Sciences, the Department of Defense, the Department of the Navy, or the U.S. Government.

\section{References}

Afifi, T. O., Boman, J., Fleisher, W., \& Sareen, J. (2009). The relationship between child abuse, parental divorce, and lifetime mental disorders and suicidality in a nationally representative adult sample. Child Abuse \& Neglect, 33(3), 139-147. 
Agerbo, E., Nordentoft, M., \& Mortensen, P. B. (2002). Familial, psychiatric, and socioeconomic risk factors for suicide in young people: Nested case-control study. British Medical Journal, 325(7355), 74-77.

Beck, A. T., Steer, R. A., \& Brown, G. K. (1996). Manual for the Beck Depression Inventory-II. San Antonio, TX: Psychological Corporation.

Borowsky, I. W., Ireland, M., \& Resnick, M. D. (2001). Adolescent suicide attempts: Risks and protectors. Pediatrics, 107(3), 485-493. doi:10.1542/peds.107.3.485.

Brenner, L. A., Gutierrez, P. M., Cornette, M. M., Betthauser, L. M., Bahraini, N., \& Staves, P. J. (2008). A qualitative study of potential suicide risk factors in returning combat veterans. Journal of Mental Health Counseling, 30(3), 211-225.

Brent, D. A. (1995). Risk factors for adolescent suicide and suicidal behavior: Mental and substance abuse disorders, family environmental factors, and life stress. Suicide and Life-Threatening Behavior, 25(Suppl.), 52-63.

Brent, D. A., Baugher, M., Bridge, J., Chen, T., \& Chiappetta, L. (1999). Age- and sex-related risk factors for adolescent suicide. Journal of the American Academy of Child and Adolescent Psychiatry, 38(12), 1497-1505.

Brent, D. A., \& Mann, J. J. (2005). Family genetic studies, suicide, and suicidal behavior. American Journal of Medical Genetics Part C, Seminars in Medical Genetics, 133C, 13-24. doi:10.1002/ajmg.c.30042.

Bursztein, C., \& Apter, A. (2009). Adolescent suicide. Current Opinion in Psychiatry, 22(1), 1-6. doi:10.1097/YCO. 0b013e3283155508.

Centers for Disease Control and Prevention. (2010). Youth risk behavior surveillance-United States, 2009. Morbidity and Mortality Weekly Report, 59(SS-5), 9-10. Retrieved August 31, 2010, from http://www.cdc.gov/mmwr/pdf/ss/ss5905.pdf

Cohen, N. J., Coyne, J. C., \& Duvall, J. D. (1996). Parents'sense of "entitlement" in adoptive and nonadoptive families. Family Process, 35(4), 441-456.

Corso, P. S., Mercy, J. A., Simon, T. R., Finkelstein, E. A., \& Miller, T. R. (2007). Medical costs and productivity losses due to interpersonal and self-directed violence in the United States. American Journal of Preventive Medicine, 32(6), 474-482.

Dube, S. R., Anda, R. F., Felitti, V. J., Chapman, D. P., Williamson, D. F., \& Giles, W. H. (2001). Childhood abuse, household dysfunction, and the risk of attempted suicide throughout the lifespan: Findings from the adverse childhood experiences study. Journal of the American Medical Association, 286(24), 3089-3096. doi:10.1001/jama.286.24.3089.

Goldney, R. D., Wilson, D., Dal Grande, E., Fisher, L. J., \& McFarlane, A. C. (2000). Suicidal ideation in a random community sample: Attributable risk due to depression and psychosocial and traumatic events. Australian and New Zealand Journal of Psychiatry, 34(1), 98-106.

Goldstein, T. R., Birmaher, B., Axelson, D., Goldstein, B. I., Gill, M. K., \& Esposito-Smythers, C., ... Keller, M. (2009). Family environment and suicidal ideation among bipolar youth.
Archives of Suicide Research, 13(4), 378-388. doi:10.1080/ 13811110903266699.

Gould, M. S., King, R., Greenwald, S., Fisher, P., Schwab-Stone, M., \& Kramer, R., . . Shaffer, D. (1998). Psychopathology associated with suicidal ideation and attempts among children and adolescents. Journal of the American Academy of Child and Adolescent Psychiatry, 37(9), 915-923.

Grøholt, B., Ekeberg, Ø., Wichstrøm, L., \& Haldorsen, T. (2000). Young suicide attempters: A comparison between a clinical and an epidemiological sample. Journal of the American Academy of Child and Adolescent Psychiatry, 39(7), 868-875.

Hagerty, B. M., \& Patusky, K. (1995). Developing a measure of sense of belonging. Nursing Research, 44(1), 9-13.

Hagerty, B. M., Williams, R. A., Coyne, J. C., \& Early, M. R. (1996). Sense of belonging and indicators of social and psychological functioning. Archives of Psychiatric Nursing, 10(4), 235-244.

Hagerty, B. M., Williams, R. A., \& Oe, H. (2002). Childhood antecedents of adult sense of belonging. Journal of Clinical Psychology, 58(7), 793-801. doi:10.1002/jclp.2007.

Hardt, J., Sidor, A., Nickel, R., Kappis, B., Petrak, P., \& Egle, U. T. (2008). Childhood adversities and suicide attempts: A retrospective study. Journal of Family Violence, 23(8), 713-718. doi:10.1007/s10896-008-9196-1.

Hill, D. L. (2009). Relationship between sense of belonging as connectedness and suicide in American Indians. Archives of Psychiatric Nursing, 23(1), 65-74. doi:10.1016/j.apnu.2008.03.003.

Kupfer, D. J., Detre, T., \& Koral, J. (1974). “Deviant” behavior patterns in school children, application of $\mathrm{KDS}^{\mathrm{TM}}-14$. Psychological Reports, 35(1), 183-191.

Lawson, D. M. (2009). Understanding and treating children who experience interpersonal maltreatment: Empirical findings. Journal of Counseling and Development, 87(2), 204-215.

Lewinsohn, P. M., Rohde, P., \& Seeley, J. R. (1996). Adolescent suicidal ideation and attempts: Prevalence, risk factors, and clinical implications. Clinical Psychology: Science and Practice, 3(1), 25-46.

May-Chahal, C., \& Cawson, P. (2005). Measuring child maltreatment in the United Kingdom: A study of the prevalence of child abuse and neglect. Child Abuse \& Neglect, 29(9), 969-984.

McKinley, J. C., Jr. (2010). Despite army efforts, soldier suicides continue. The New York Times. Retrieved October 10, 2010, from The New York Times Web site: http://www.nytimes.com/ 2010/10/11/us/11suicides.html?_r=2\&emc=eta1

McLaren, S., \& Challis, C. (2009). Resilience among men farmers: The protective roles of social support and sense of belonging in the depression-suicidal ideation relation. Death Studies, 33(3), 262-276. doi:10.1080/07481180802671985.

Molnar, B. E., Berkman, L. F., \& Buka, S. L. (2001). Psychopathology, childhood sexual abuse and other childhood adversities: Relative links to subsequent suicidal behavior in the U.S. Psychological Medicine, 31(6), 965-977. doi:10.1017/ S003329170105432.

National Center for Health Statistics. (2010). Health, United States, 2009: With special feature on medical technology (DHHS 
Publication No. 2010-1232). Retrieved August 31, 2010, from http://www.cdc.gov/nchs/data/hus/hus09.pdf

Pfeffer, C. R. (2001). Diagnosis of childhood and adolescent suicidal behavior: Unmet needs for suicide prevention. Biological Psychiatry, 49(12), 1055-1061.

Pfeffer, C. R., Karus, D., Siegel, K., \& Jiang, H. (2000). Child survivors of parental death from cancer or suicide: Depressive and behavioral outcomes. Psycho-Oncology, 9(1), 1-10.

Sargent, J., Williams, R. A., Hagerty, B., Lynch-Sauer, J., \& Hoyle, K. (2002). Sense of belonging as a buffer against depressive symptoms. Journal of the American Psychiatric Nurses Association, 8(4), 120-129. doi:10.1067/mpn.2002.127290.

Shaffer, D., Gould, M. S., Fisher, P., \& Trautman, P. (1996). Psychiatric diagnosis in child and adolescent suicide [Abstract]. Archives of General Psychiatry, 53(4), 339. Abstract retrieved from http://www.lib.umich.edu/articles/details/ FETCH-webofscience_primary_A1996UD952000101

Shafii, M., Steltz-Lenarsky, J., Derrick, A. M., Beckner, C., \& Whittinghill, J. R. (1988). Comorbidity of mental disorders in the post-mortem diagnosis of completed suicide in children and adolescents. Journal of Affective Disorders, 15(3), 227-233.
U.S. Department of Health and Human Services. (2000). Healthy People 2010: Understanding and improving health (Stock Number 017-001-001-00-550-9). Retrieved August 31, 2010, from http://www.healthypeople.gov/2010/Document/pdf/uih/ 2010uih.pdf

U.S. Department of Health and Human Services. Office of Disease Prevention and Health Promotion. (2011). Healthy People 2020. Washington, DC: Author. Retrieved from http:// healthypeople.gov/2020/topicsobjectives2020/objectiveslist. aspx?topicId=28. Accessed September 9, 2011.

Van Orden, K. A., Witte, T. K., Cukrowicz, K. C., Braithwaite, S. R., Selby, E. A., \& Joiner, T. E., Jr. (2010). The interpersonal theory of suicide. Psychological Review, 117(2), 575-600. doi:10.1037/ a0018697.

Williams, R. A., Hagerty, B. M., Andrei, A., Yousha, S. M., Hirth, R. A., \& Hoyle, K. S. (2007). STARS: Strategies to assist navy recruits' success. Military Medicine, 172(9), 942-949.

Williams, R. A., Hagerty, B. M., Yousha, S. M., Horrocks, J., Hoyle, K. S., \& Liu, D. (2004). Psychosocial effects of the Boot Strap intervention in Navy recruits. Military Medicine, 169(10), 814-820. 